\title{
Efficacy of argon plasma coagulation compared with topical formalin application for chronic radiation proctopathy
}

\author{
AA Alfadhli FRCPC ${ }^{1}$, WM Alazmi FRCPC ${ }^{1}$, T Ponich FRCPC ${ }^{2}$, JM Howard FRCPC ${ }^{2}$, \\ I Prokopiw FRCPC ${ }^{2}$, A Alaqeel MD², JC Gregor FRCPC ${ }^{2}$
}

\begin{abstract}
AA Alfadhli, WM Alazmi, T Ponich, et al. Efficacy of argon plasma coagulation compared with topical formalin application for chronic radiation proctopathy. Can J Gastroenterol 2008; 22(2):129-132.
\end{abstract}

BACKGROUND: Chronic radiation proctopathy (CRP) is a troublesome complication of radiotherapy to the pelvis for which current treatment modalities are suboptimal. Currently, the application of formalin to the rectal mucosa (AFR) and thermal ablation with argon plasma coagulation (APC) are the most promising options.

OBJECTIVE: To compare the efficacy and safety of AFR with APC for CRP.

PATIENTS AND METHODS: Records of 22 patients (male to female ratio, 19:3; mean age, 74 years) who received either APC or AFR for chronic hematochezia caused by CRP, and who were evaluated and treated between May 1998 and April 2002, were reviewed. Complete evaluations were made three months after completion of each therapeutic modality. Patients were considered to be responders if there was a $10 \%$ increase in hemoglobin from baseline or complete normalization of hemoglobin (male patients, higher than $130 \mathrm{~g} / \mathrm{L}$; female patients, higher than $115 \mathrm{~g} / \mathrm{L}$ ) without the requirement for blood transfusion.

RESULTS: The mean hemoglobin level before therapy was $107 \mathrm{~g} / \mathrm{L}$. Patients received an average of 1.78 sessions for APC and 1.81 sessions for AFR. Eleven patients (50\%) were treated with APC alone, eight patients $(36 \%)$ with AFR alone and three (14\%) with both modalities (two with AFR followed by APC, and one with APC followed by AFR). Eleven of 14 patients (79\%) in the APC group were responders, compared with three of 11 patients $(27 \%)$ in the AFR group $(\mathrm{P}=0.017)$. In the $\mathrm{APC}$ group, seven of 11 responders required only a single session, while in the AFR group, only one patient responded after a single session. Adverse events (nausea, vomiting, flushing, abdominal cramps, rectal pain and fever) occurred in two patients after APC and in nine patients after AFR $(P=0.001)$. In the APC group, the mean hemoglobin level increase was $20 \mathrm{~g} / \mathrm{L}$ at three months follow-up, compared with $14 \mathrm{~g} / \mathrm{L}$ in the AFR group. CONCLUSION: This retrospective study suggests that APC is more effective and safe than topical AFR to control hematochezia caused by CRP. Further studies are needed to confirm this observation.

Key Words: Argon plasma coagulation; Radiation proctopathy; Topical formalin

\section{L'efficacité de la coagulation du plasma par l'argon par rapport à l'application de formaldéhyide topique en cas de proctopathie par radiation chronique}

HISTORIQUE : La proctopathie par radiation chronique (PRC) est une complication complexe de la radiothérapie du bassin, pour lesquelles les modalités de traitement actuelles sont sous-optimales. En ce moment, l'application de formaldéhyde sur la muqueuse rectale (FMR) et l'ablation thermique par coagulation du plasma par l'argon (CPA) sont les solutions les plus prometteuses.

OBJECTIF : Comparer l'efficacité et l'innocuité de la FMR par rapport à la CPA pour la PRC.

PATIENTS ET MÉTHODOLOGIE : Les auteurs ont examiné le dossier de 22 patients (ratio hommes-femmes de 19:3, âge moyen de 74 ans) qui avaient subi une CPA ou l'application de FMR pour traiter une hématochésie causée par une PRC et qui avaient été évalués et traités entre mai 1998 et avril 2002. Ils ont procédé aux évaluations complètes trois mois après avoir terminé chaque modalité thérapeutique. Les patients étaient considérés comme réagissant au traitement si leur taux d'hémoglobine avait augmenté de $10 \%$ par rapport au début ou si ce taux s'était entièrement normalisé (patients de sexe masculin, plus de $130 \mathrm{~g} / \mathrm{L}$, et de sexe féminin, plus de $115 \mathrm{~g} / \mathrm{L}$ ) sans transfusion sanguine.

RÉSULTATS : Le taux d'hémoglobine moyen avant le traitement était de $107 \mathrm{~g} / \mathrm{L}$. Les patients ont reçu en moyenne 1,78 séance de CPA et 1,81 séance de FMR. Onze patients (50\%) ont été traités seulement par CPA, huit (36\%), seulement par FMR, et trois (14\%), par les deux interventions (deux par FMR suivie d'une CPA et un par CPA suivie de l'application de FMR). Onze des 14 patients (79\%) du groupe traité par CPA ont réagi, par rapport à trois des 11 patients $(27 \%)$ du groupe traité par FMR $(\mathrm{P}=0,017)$. Dans le groupe traité par $\mathrm{CPA}$, sept des 11 personnes qui avaient réagi au traitement n'ont eu besoin que d'une séance, tandis que dans celui traité par FMR, un seul patient a réagi après une seule séance. Deux patients ont souffert d'effets secondaires (nausées, vomissements, bouffées vasomotrices, crampes abdominales, douleur rectale et fièvre) après la CPA et neuf, après l'application de FMR $(\mathrm{P}=0,001)$. Dans le groupe traité par CPA, l'augmentation moyenne du taux d'hémoglobine était de $20 \mathrm{~g} / \mathrm{L}$ au suivi de trois mois, par rapport à $14 \mathrm{~g} / \mathrm{L}$ dans le groupe traité par application de FMR.

CONCLUSION : Cette étude rétrospective indique que la CPA est plus efficace et plus sécuritaire que la FMR topique pour contrôler l'hématochésie causée par un PRC. D'autres études s'imposent pour confirmer cette observation.
Chronic radiation proctopathy (CRP) results from submuCosal damage that occurs with radiation therapy for pelvic malignancies - prostate cancer in men and cervical cancer in women. Patients undergoing this treatment often have acute side effects, such as hematochezia, tenesmus, cramping, constipation or diarrhea $(1,2)$. Medical management with corticosteroids (3), sulfasalazine (4), sucralfate enemas (5), dilute formalin (6) and salfasalazine (3) is generally ineffective. Surgical intervention, conversely, has a high incidence of morbidity. Promising advances have been made in

\footnotetext{
${ }^{1}$ Mubarak Alkabeer Hospital, Aljabrya, Kuwait; ${ }^{2}$ Division of Gastroenterology, University of Western Ontario, London, Ontario

Correspondence and reprints: Dr AA Alfadhli, Gastroenterology Unit, Department Medicine, Mubarak Alkabeer Hospital, Ministry of Health,

Kuwait, PO Box 43787, Safat, Kuwait. Telephone 965-704-1221, fax 965-531-1415, e-mail ahmadalfadhli@hotmail.com

Received for publication April 26, 2007. Accepted August 7, 2007
} 

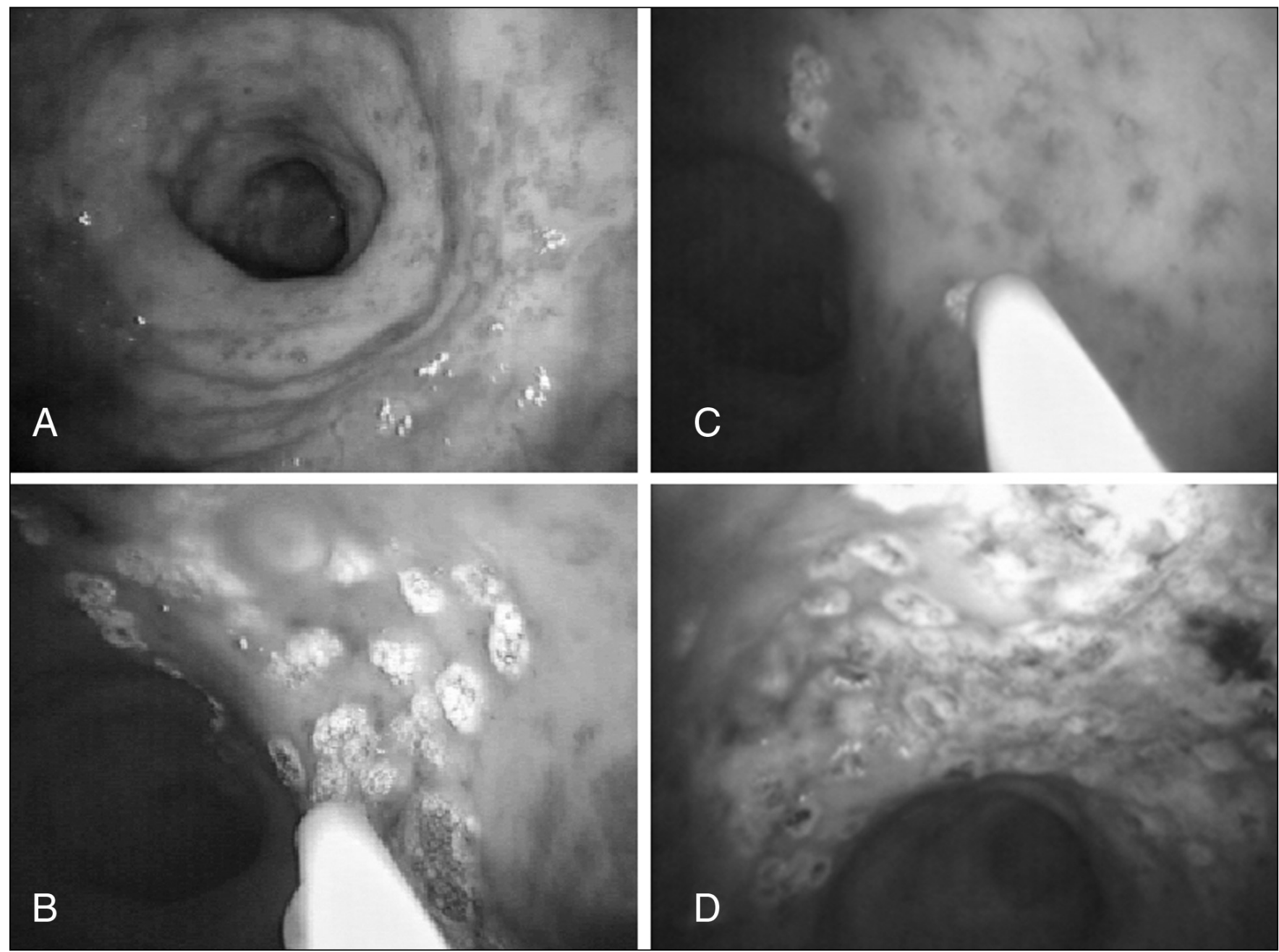

Figure 1) Colonoscopy photographs of the rectum, showing the rectal wall of a patient with chronic radiation proctopathy before argon plasma coagulation (APC) treatment (A), at the beginning of APC treatment (B), during APC treatment (C) and at the end of APC treatment (D)

endoscopic therapy, including treatment with formalin, neodymium/yttrium aluminum garnet, potassium titanyl phosphate lasers and argon plasma coagulation (APC) (7). Among the various endoscopic treatments, APC has emerged as the front runner, due to its affordability, ease of use, effectiveness and low risk of complications (8).

The objectives of the present study were to assess the efficacy and safety of APC and the application of formalin to the rectal mucosa (AFR) in the treatment of CRP, and to compare bleeding-related outcomes in patients undergoing at least one of these modalities.

\section{PATIENTS AND METHODS}

Patients with chronic hematochezia caused by CRP who were evaluated between May 1998 and April 2002 were identified. Standard informed consent was obtained from all patients before colonoscopy. Colonoscopy was performed by four different experienced endoscopists. Colonoscopy to the cecum was performed in every patient to determine the proximal extent of the disease and to exclude other possible etiologies of bleeding. Conscious sedation was achieved in all patients using midazolam and meperidine.

One group of patients was treated with the ERBE Argon Plasma Coagulator ICC 200 (ERBE USA, USA). The APC probe was end-firing (Olympus America, USA). The argon gas flow rate that was used ranged from $1.2 \mathrm{~L} / \mathrm{min}$ to $2 \mathrm{~L} / \mathrm{min}$, with the electrical power setting ranging from $45 \mathrm{~W}$ to $50 \mathrm{~W}$, and probe size ranging from $2.7 \mathrm{~mm}$ to $3.2 \mathrm{~mm}$ diameter. An effort was made to treat individual telangiectasias and, whenever possible, to avoid 'painting' the rectal wall, thereby minimizing ulceration (Figure 1). Whenever possible, lesions were treated in a single session. In all cases, telangiectatic lesions were treated first on forward view until no further lesions were visible, and then the instrument was retroflexed and treatment continued. All patients were treated on an outpatient basis. Patients in whom it appeared endoscopically that all telangiectatic lesions had been treated in one session were asked to return only if bleeding persisted. Follow-up was by completed review of medical records.

The other group was treated with $4 \%$ dilute formalin. First, protective cream was applied to the anal area and the buttocks. Then, diluted formalin was applied through the scope to cover the entire area involved with telangiectasia, whenever possible. The patient was then asked to turn every 5 min to make sure that formalin contacted the whole surface of the rectum.

Patients were considered to be responders if there was a 10\% increase in hemoglobin level from baseline or complete normalization of hemoglobin (men, higher than $130 \mathrm{~g} / \mathrm{L}$; women, 


\section{TABLE 1}

Main characteristics of 22 patients who received treatment with argon plasma coagulation (APC) or application of formalin to the rectal mucosa (AFR)

\begin{tabular}{|c|c|c|}
\hline \multirow[b]{2}{*}{ Characteristic } & \multicolumn{2}{|c|}{ Treatment type* } \\
\hline & $\operatorname{APC}(n=14)$ & $\operatorname{AFR}(n=11)$ \\
\hline Mean age, years & 74.7 & 71.7 \\
\hline Men:women, $\mathrm{n}$ & $11: 3$ & $10: 1$ \\
\hline Cancer type, prostate:uterine, $\mathrm{n}$ & $11: 3$ & $10: 1$ \\
\hline Mean number of sessions & 1.78 & 1.81 \\
\hline Mean hemoglobin level (pretreatment), g/L & 105.50 & 106.50 \\
\hline
\end{tabular}

${ }^{*}$ Three patients received both APC and AFR treatment

higher than $115 \mathrm{~g} / \mathrm{L}$ ) without the requirement for blood transfusion. Adverse events were defined as the development of one of the following within seven days of the procedure: nausea and/or vomiting, flushing, and rectal pain and/or fever.

\section{Statistical analysis}

The paired Student's $t$ test was used to compare different continuous variables before and after treatment. Fisher's exact test was used to compare the efficacy and safety of APC with AFR for radiation-induced proctopathy. $\mathrm{P} \leq 0.05$ was considered a significant value.

\section{RESULTS}

Twenty-two patients (19 men) were identified. The mean \pm SD age was $73.9 \pm 6.9$ years. The mean hemoglobin value before endoscopic therapy was $107 \mathrm{~g} / \mathrm{L}$ (range $71 \mathrm{~g} / \mathrm{L}$ to $133 \mathrm{~g} / \mathrm{L}$ ). The mean number of sessions received by patients was 1.78 for the APC group and 1.81 for the AFR group (Table 1). The mean duration of the APC sessions was $31 \mathrm{~min}$ (range $10 \mathrm{~min}$ to $75 \mathrm{~min}$ ).

Eleven patients (50\%) received APC, while eight patients (36\%) received AFR, and three patients (14\%) received both APC and AFR (two with AFR followed by APC, and one with APC followed by AFR). Eleven patients (78.5\%) in the APC group responded, compared with only three patients $(27.2 \%)$ in the AFR group $(\mathrm{P}=0.017)$. Moreover, seven of the nine patients (63.6\%) who responded in the APC group required only a single session, compared with only one patient $(33.3 \%)$ in the AFR group.

Adverse effects were more often statistically significant in patients who received AFR (nine of 11 patients, $81.8 \%$ ) than in those who received APC (two of 14, 33.3\%; $\mathrm{P}=0.001$ ). There were no statistically significant differences in pre- or posttreatment hemoglobin levels in both groups (Tables 1 and 2).

\section{DISCUSSION}

Historically, CRP has been treated pharmacologically with topical and oral agents. However, this approach is unsatisfactory. Surgery, with its high rate of morbidity in patients with prior radiation, is not a desirable option. Endoscopic therapy has proven successful in stopping bleeding from CRP, in addition to providing symptomatic relief by reducing the frequency of hematochezia and transfusion requirements. Initially, endoscopists had used the heater and bipolar probes $(9,10)$, then the neodymium/yttrium aluminum garnet $(11,12)$ and potassium titanyl phosphate lasers $(13,14)$, which were each effective. Formalin administration through a rigid scope also proved
TABLE 2

Comparison of the outcomes of argon plasma coagulation (APC) and the application of formalin to the rectal mucosa (AFR) for the treatment of chronic radiation proctopathy $(n=22)$

\begin{tabular}{lccc}
\hline & \multicolumn{2}{c}{ Treatment type* $^{*}$} & \\
\cline { 2 - 3 } Outcome & APC (n=14) & AFR (n=11) & P \\
\hline Response, \% & 78.5 & 27.2 & 0.017 \\
Single session responders, \% & 63.6 & 33.3 & NS \\
Adverse effects, \% & 33.3 & 81.8 & 0.001 \\
Mean post-treatment hemoglobin & 125.5 & 120.1 & NS \\
level, g/L & & & \\
\hline *Three patients received both APC & & \\
\hline
\end{tabular}

effective $(15,16)$. The use of APC by endoscopy began in 1994 and has become an attractive treatment option, because it is a noncontact approach that is efficient, effective, relatively safe and well tolerated (15).

Formalin use for CRP was first reported by Rubinstein et al (16) in 1986. The treatment led to cessation of the bleeding and resolution of the symptoms for the 14-month follow-up period. A few other studies have been conducted since then. Most used 4\% dilute formalin applied through a rigid proctoscope or bivalve retractor under local, spinal or general anesthesia. Application is completed either by instillation or direct application of gauze, soaked in solution. The formalin seems to work by sclerosing the telangiectatic mucosal vessels. Reported side effects include anal stenosis, fissures, fecal incontinence and ulceration of mucosa (17-20).

The use of APC has gained popularity since its initial use with a flexible endoscope in 1994. APC is an innovative, notouch electrocoagulation technique used in the treatment of hemorrhagic digestive malformations. It consists of a highfrequency monopolar electrosurgical generator, a source of argon gas, a gas flow meter, flexible delivery catheters, a foot switch for energy and gas delivery, and a grounding pad $(15,21)$. There have been several case series involving the use of APC for radiation proctopathy (22-24). These studies have demonstrated the superior efficacy and safety of APC in the treatment of CRP.

The present study described the experience of using APC in the treatment of CRP. In contrast with other studies, we compared the outcomes of two proven modalities that are frequently used in the treatment of CRP, hence demonstrating the favourable modality for the management of CRP patients. Our results show that APC is more effective and safer than AFR in the treatment of CRP. APC also improves the hemoglobin level in these patients more effectively than AFR. The mean number of sessions required in patients who had APC was 1.78 , which is nearly the same as AFR (1.81), but the rate of single-session APC responders (63.6\%) was almost double that of the AFR group (33.3\%). Our results are in agreement with those of Fantin et al (23) and Saurin et al (25). Whether this reflects a specific effort during APC to treat all telangiectatic lesions in a single session is uncertain.

Because our study was retrospective in nature, it lacked the proper randomization and follow-up. The severity of proctitis was not assessed in patients before endoscopic treatment; hence, the severity of proctitis could have been different in each group, and that would have affected their response to each modality. In addition, the modality used in each patient 
was subjected to the treating endoscopist's decision. Moreover, the lag time between radiation and endoscopic therapy was not known for some patients. These inherent drawbacks of the retrospective chart review analysis might have considerably affected our results and conclusion. Therefore, a randomized, controlled trial is needed to compare the two endoscopic modalities in the treatment of CRP.

Patients who received APC as a treatment had less shortterm and long-term complications $(33.3 \%)$ than those who received AFR (81.8\%); similar results have been reported by Fantin et al (23) and Villavicencio et al (22), who found that APC application for the treatment of CRP resulted in less

\section{REFERENCES}

1. Johnston MJ, Robertson GM, Frizelle FA. Management of late complications of pelvic radiation in the rectum and anus: A review. Dis Colon Rectum 2003;46:247-59.

2. Ajlouni M. Radiation-induced proctitis. Curr Treat Options Gastroenterol 1999;2:20-6.

3. Goldstein F, Khoury J, Thorton JJ. Treatment of chronic radiation enteritis and colitis with salicylazosulfapyridine and systemic corticosteroids: A pilot study. Am J Gastroenterol 1 1976;65:201-8.

4. Baum CA, Biddle WL, Miner PB Jr. Failure of 5-aminosalicylic acid enemas to improve chronic radiation proctitis. Dig Dis Sci 1989;34:758-60.

5. Kochhar R, Sharma SC, Gupta BB, Mehta SK. Rectal sucralfate in radiation proctitis. Lancet 1988;2:400.

6. Seow-Cheon F, Goh HS, Eu KW, Ho YH, Tay SK. A simple and effective treatment for hemorrhagic radiation proctitis using formalin. Dis Colon Rectum 1993;36:135-8.

7. Tjandra JJ, Sengupta S. Argon plasma coagulation is an effective treatment for refractory hemorrhagic radiation proctitis. Dis Colon Rectum 2001;44:1759-65.

8. Rotondano G, Bianco MA, Marmo R, Piscopo R, Cipolletta L. Longterm outcome of argon plasma coagulation therapy for bleeding caused by chronic radiation proctopathy. Dig Liver Dis 2003;35:806-10.

9. Fuentes D, Monserat R, Isern AM, et al. [Colitis due to radiation: Endoscopic management with heat probe]. G E N 1993;47:165-7.

10. Jensen DM, Machicado FA, Cheng S, Jensen ME, Jutabha R. A randomized prospective study of endoscopic bipolar electrocoagulation and heater probe treatment of chronic rectal bleeding from radiation telangiectasia. Gastrointest Endosc 1997;45:20-5.

11. Leuchter RS, Petrilli ES, Dwyer RM, Hacker NF, Castaldo TW, Lagasse LD. Nd:YAG laser therapy of rectosigmoid bleeding due to radiation injury. Obstet Gynecol 1982;59(6 Suppl):65S-7S.

12. Barbatzas C, Spencer GM, Thorpe SM, Sargeant LR, Brown SG. $\mathrm{Nd}$ :YAG laser treatment for bleeding from radiation proctitis. Endoscopy 1996;28:497-500. (Erratum in 1997;29:47).

13. Pritikin J, Weinman D, Harmatz A, Young H. Endoscopic laser therapy in gastroenterology. West J Med 1992;157:48-54. short-term and long-term complications than other modalities. Short-term and long-term complications are likely to be a result of more extensive treatment during a single session. Hence, it would be reasonable to apply treatment over multiple sessions to reduce the frequency and severity of complications.

\section{CONCLUSIONS}

APC is significantly more effective and safer than topical AFR to control hematochezia caused by radiation proctopathy. Further studies are needed to determine optimal power settings and method of delivery, and whether the surface area treated per session should be limited.

14. Taylor JG, Disario JA, Bjorkman DJ. KTP laser therapy for bleeding from chronic radiation proctopathy. Gastrointest Endosc 2000;52:353-7.

15. Wilson SA, Rex DK. Endoscopic treatment of chronic radiation proctopathy. Curr Opin Gastroenterol 2006;22:536-40.

16. Rubinstein E, Ibsen T, Rasmussen RB, Reimer E, Sorensen BL. Formalin treatment of radiation-induced hemorrhagic proctitis. Am J Gastroenterol 1986;81:44-5.

17. de Parades V, Etienney I, Bauer P, et al. Formalin application in the treatment of chronic radiation-induced hemorrhagic proctitis - an effective but not risk-free procedure: A prospective study of 33 patients. Dis Colon Rectum 2005;48:1535-41.

18. Seow-Choen F, Goh HS, Eu KW, Ho YH, Tay SK. A simple and effective treatment for hemorrhagic radiation procititis using formalin. Dis Colon Rectum 1993;36:135-8.

19. Saclarides TJ, King DG, Franklin JL, Doolas A. Formalin instillation for refractory radiation-induced hemorrhagic proctits. Report of 16 patients. Dis Colon Rectum 1996;39:196-9.

20. Chautems RC, Delgadillo X, Rubbia-Brandt L, DeLeaval JP, Marti MC, Roche B. Formaldehyde application for haemorrhagic radiation-induced proctitis: A clinical and histological study. Colorectal Dis 2003;5:24-8.

21. Ginsberg GG, Barkun AN, Bosco JJ, et al. The argon plasma coagulator: February 2002. Gastrointest Endosc 2002;55:807-10.

22. Villavicencio RT, Rex DK, Rahmani E. Efficacy and complications of argon plasma coagulation for hematochezia related to radiation proctopathy. Gastrointest Endosc 2002;55:70-4.

23. Fantin AC, Binek J, Suter WR, Meyenberger C. Argon beam coagulation for treatment of symptomatic radiation-induced proctitis. Gastrointestest Endosc 1999;49:515-8.

24. Sebastian S, O'Connor H, O'Morain C, Buckley M. Argon plasma coagulation as first-line treatment for chronic radiation proctopathy. J Gastroenterol Hepatol 2004;19:1169-73.

25. Saurin JC, Cohelo J, Lepretre J, et al. Argon plasma coagulation (APC) efficiently controls bleeding in patients with watermelon stomach or radiation proctitis. Gastrointest Endosc 1999;49:AB169. (Abst) 


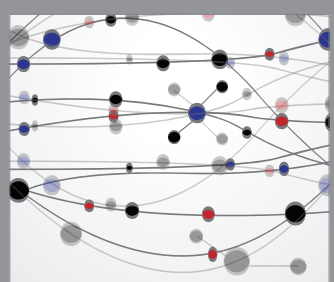

The Scientific World Journal
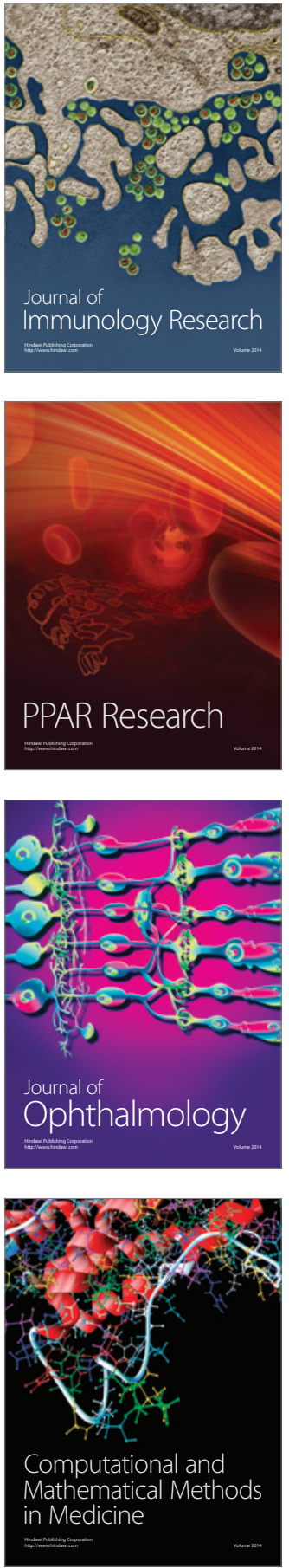

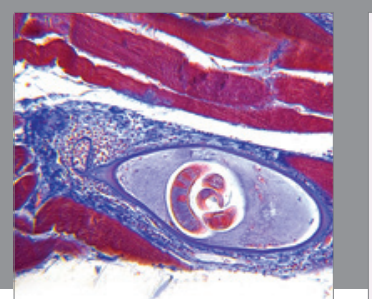

Gastroenterology Research and Practice

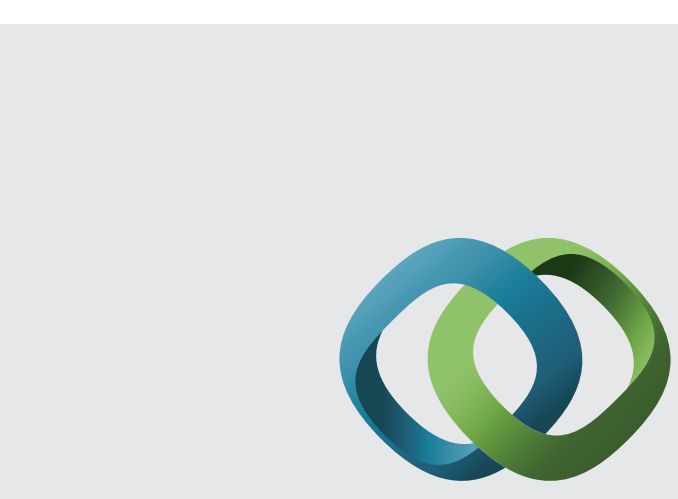

\section{Hindawi}

Submit your manuscripts at

http://www.hindawi.com
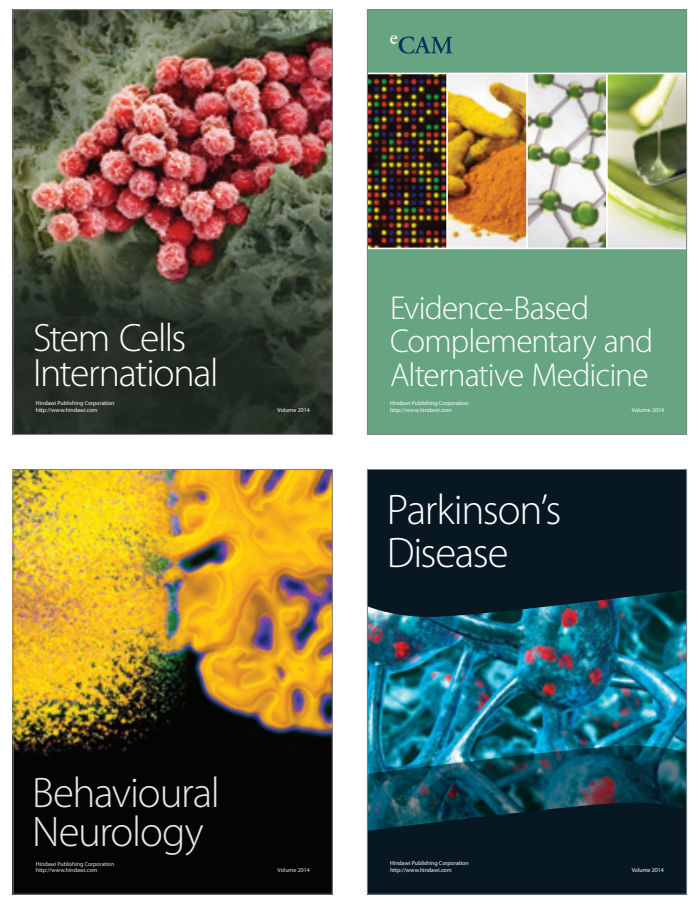
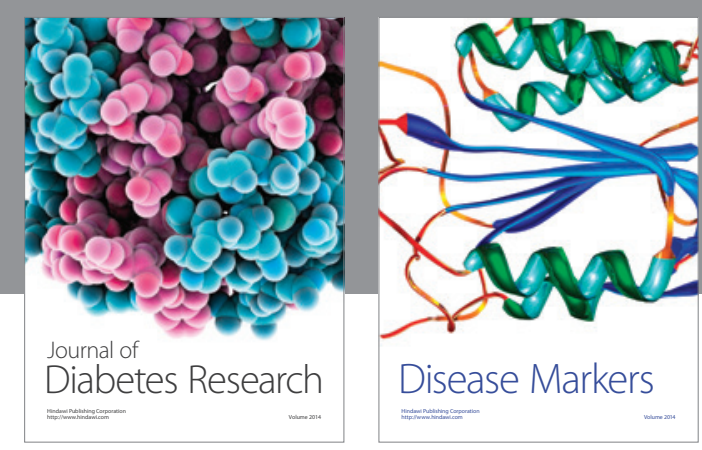

Disease Markers
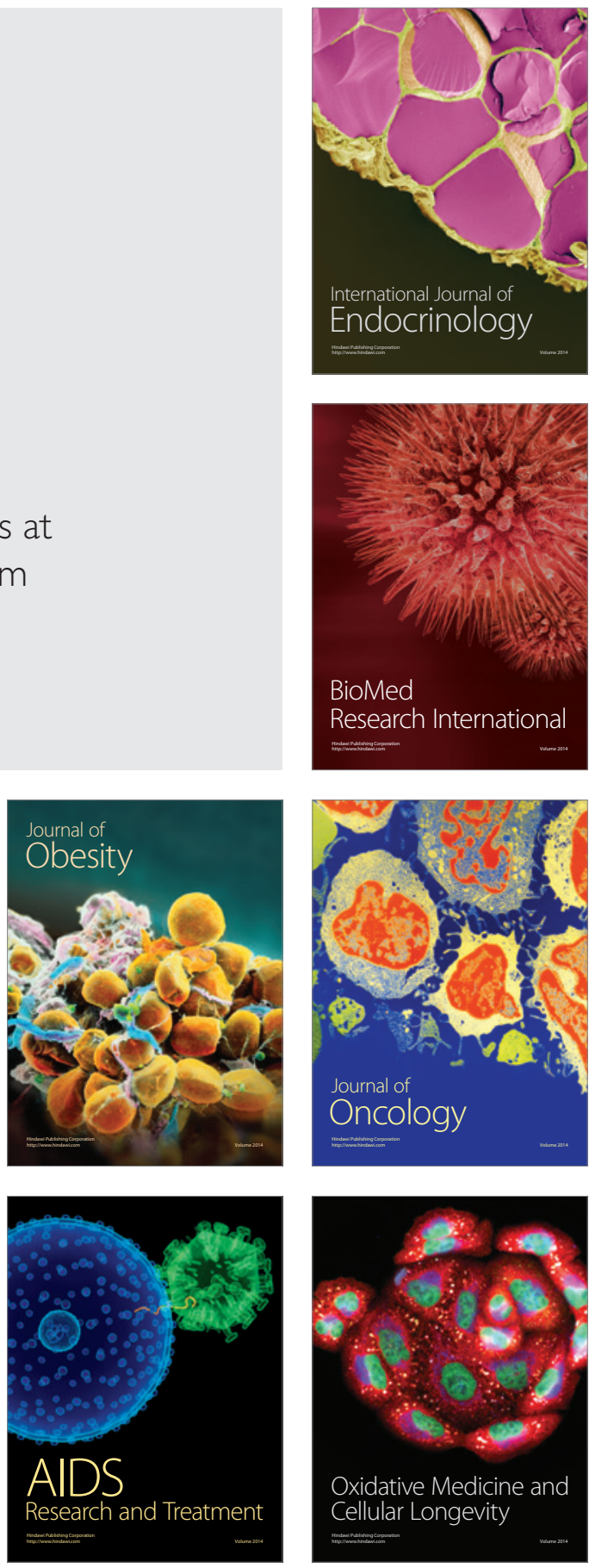